\title{
How does income affect mental health and health behaviours? A quasi-experimental study of the earned income tax credit
}

\author{
Laura Shields-Zeeman, ${ }^{1,2}$ Daniel F. Collin, ${ }^{1}$ Akansha Batra, ${ }^{3}$ Rita Hamad (1) 1,4
}

\begin{abstract}
- Additional supplemental material is published online only. To view, please visit the journal online (http://dx doi.org/10.1136/jech-2020214841)
\end{abstract}

${ }^{1}$ Department of Family \& Community Medicine, University of California San Francisco, San Francisco, California, USA ${ }^{2}$ Netherlands Institute for Mental Health and Addiction, Utrecht, The Netherlands ${ }^{3}$ Department of Epidemiology \& Biostatistics, University of California San Francisco, San Francisco, California, USA ${ }^{4}$ Philip R. Lee Institute for Health Policy Studies, University of California San Francisco, San Francisco, California, USA

\section{Correspondence to} Dr Laura Shields-Zeeman, Family and Community Medicine, University of California San Francisco, San Francisco California, USA

Ishields-zeeman@trimbos.nl

Received 8 June 2020 Revised 27 January 2021 Accepted 21 March 2021

Published Online First 14 May 2021

ABSTRACT

Background Although research has repeatedly demonstrated the association between poverty, mental health, and health behaviours, there is limited evidence on the effects of interventions to improve these outcomes by addressing poverty directly. Moreover, most prior studies are often confounded by unobserved characteristics of individuals, making it difficult to inform possible interventions. We addressed this gap in the literature by leveraging quasi-random variation in the earned income tax credit (EITC) — the largest US poverty alleviation programme for families with children-to examine the effects on overall health, psychological distress, smoking, and alcohol consumption.

Methods We used a large diverse national sample drawn from the Panel Study of Income Dynamics $(\mathrm{N}=34824)$. We first conducted ordinary least squares (OLS) models to estimate the association of income and the EITC with the outcomes of interest. We subsequently employed a quasi-experimental instrumental variables

(IV) analysis - in which EITC refund size was the instrument-to estimate the effect of income itself. Results In OLS models, higher income was associated with reductions in psychological distress, increased drinking, increased smoking, and more cigarettes per day, and larger EITC refunds were associated with reductions in psychological distress. In IV models, higher income was associated with decreased psychological distress.

Conclusion These results suggest that typical correlational studies of the health effects of income may be confounded, although results may not generalise to income distributed in different ways than the EITC. The findings also provide valuable information for policymakers and researchers seeking to address socioeconomic disparities in mental health.

\section{INTRODUCTION}

It is well recognised that income, and conversely, poverty, are important social determinants of physical and mental health. ${ }^{1}$ In particular, poverty is associated with greater risk of common mental disorders. ${ }^{23}$ In the US, the prevalence of depression is higher for those in the lowest $(9.8 \%)$ compared with the highest $(5.7 \%)$ income groups. ${ }^{4}$ There are numerous hypothesised mechanistic pathways that may explain these associations (figure 1). Poverty is thought to reduce individuals' 'cognitive bandwidth', which can result in changes to decisionmaking abilities and engagement in risky health behaviours. ${ }^{5}$ Low-income populations may also have greater exposure to chronic stressors, amplifying the risk of developing or exacerbating mental health problems. ${ }^{6}$ Poverty or low socioeconomic status has been associated with a greater likelihood of smoking and problematic alcohol use, ${ }^{78}$ perhaps because substance use may be a coping mechanism for stress. ${ }^{7}$ Moreover, increased income can also be used to purchase more cigarettes and alcohol. ${ }^{9}$ The type of income may also matter: some studies have shown that infrequent cash benefits increase expenditures on 'temptation' goods such as alcohol relative to more frequent benefits. ${ }^{10}$ Income insecurity may impact healthcare utilisation (eg, reduced access to, use of, and quality of mental healthcare). ${ }^{11}$

Despite the associations between income and health, existing evidence is often correlational, and there are limited studies-especially in the US - that test the effects of interventions or policies to address poverty on mental health and health behaviours. Policies focusing on reducing social and economic risk factors have the potential to improve health disparities, although traditional study designs for poverty alleviation interventions face challenges due to the expense of administering financial interventions and long-term follow-up of participants. Quasi-experimental methods that leverage existing variation in economic policies may be helpful in examining the links between income and health. In the US, the earned income tax credit (EITC) is the largest poverty alleviation programme for families with children, with an estimated 25 million recipients receiving over US $\$ 60$ billion in $2018 .^{12}$ Initiated in 1975, the EITC is a federal programme that provides tax refunds to low-income working families. Eligibility is based on earned income, family size, marital status, and age. The average payment size for a family with children is approximately US $\$ 3000$, distributed as a tax refund. ${ }^{13}$ The EITC has been shown to reduce poverty ${ }^{1415}$ and improve housing outcomes. ${ }^{16}$ Several studies have examined the EITC's health effects, finding improvements in food security, ${ }^{17}$ health insurance coverage,${ }^{18}$ infant birth weight, and other child health outcomes. ${ }^{19} 20$ Studies of the effect on mental health and health behaviours are limited. One study found that state EITC programmes reduced suicides among loweducated adults, ${ }^{21}$ while another found improved mental health among EITC-eligible mothers. ${ }^{22}$ The EITC has been associated with reduced tobacco use, ${ }^{17} 23$ particularly among mothers, ${ }^{19}$ although one study found that higher income from the EITC is associated with an increase in the number 


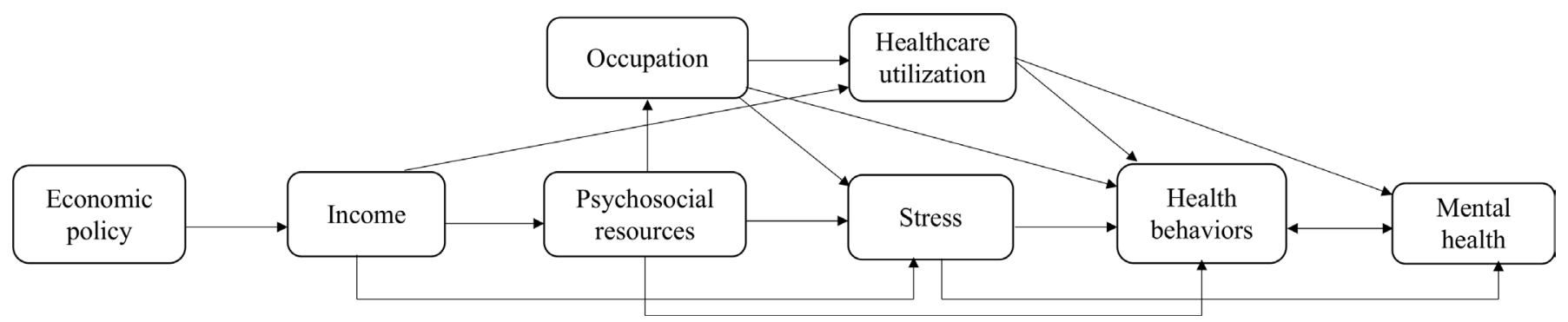

Figure 1 Conceptual model linking income with mental health and health behaviours.

of cigarettes consumed and a decrease in smoking cessation. ${ }^{24}$ Two prior studies found that the EITC had no effect on alcohol use. ${ }^{17} 25$ Nearly all these studies used historical data prior to 2000, and most estimated EITC eligibility using proxies such as low educational attainment or ecological measures of state EITC implementation. In the context of a shifting political climate and changes to other safety net programmes, contemporary evidence is needed to understand the effects of income and economic policies on mental health and health behaviours.

The present study helps to fill these gaps in the literature. The aim was to assess the effect of an economic policy on mental health and health behaviours among working low-income families in the United States, leveraging variation in EITC policy through a quasi-experimental analysis in a large national sample of US adults with granular information on EITC eligibility.

\section{METHODS}

\section{Sample}

Data were drawn from the Panel Study of Income Dynamics (PSID), a large national household cohort study. ${ }^{26}$ The PSID has been conducted annually since 1968 and biennially since 1997. We restricted our sample to data collected since 1985 (the earliest year when at least one of the outcomes of interest was available) through 2015 (the most recent survey wave available when data analysis began) $(\mathrm{N}=65047)$. We further restricted our sample to heads of households and spouses, as these were the participants for whom PSID asked the outcomes of interest $(\mathrm{N}=36262)$. Next, we restricted our analysis to those with data on at least one of the outcomes of interest $(\mathrm{N}=35481)$. Finally, we restricted the sample to observations with complete cases $(\mathrm{N}=34824)$. Because PSID is a cohort study, individuals are interviewed repeatedly over time, resulting in 289877 total observations. We account for the panel nature of the data set with the inclusion of individual-level fixed effects and clustered standard errors (SEs, described below).

\section{Health outcomes}

We examined psychological distress, overall health, alcohol use, and smoking. Psychological distress was assessed using the Kessler-6 scale (K6), a widely used screening tool for mental health problems. ${ }^{27}$ Higher scores indicate higher levels of psychological distress (range 0-24). Overall health, self-reported as a 5 -item scale, was coded as a binary variable indicating very good or excellent health versus good, fair, or poor health. Selfrated health is a validated predictor of mental health, health behaviours, and mortality. ${ }^{28}$ Alcohol was assessed as current consumption (binary) and whether the individual consumed $3+$ drinks per day (binary, zero for non-drinkers). While the latter does not correspond directly to binge drinking (defined as $4+$ drinks per day for women and $5+$ for men), PSID did not consistently include a continuous measure of the number of drinks consumed. Smoking was assessed as currently smoking (binary) and the number of cigarettes per day (continuous, zero for non-smokers).

Of note, the K6 was asked for either the head of household or spouse (preferentially the head), while other outcomes were available for both the head and spouse. Also, not all outcomes were assessed in all survey waves (online supplemental table 1), resulting in different numbers of observations for each regression (table 1).

\section{Instrument}

The amount of EITC refund for which an individual was eligible, including both federal and state refunds, served as the instrumental variable for the analysis described below. This amount was computed using the Taxsim 27 package for Stata, which calculates

Table 1 Sample characteristics, Panel Study of Income Dynamics, 1985-2015

\begin{tabular}{|c|c|c|}
\hline Panel A: demographics & Mean (SD) or \% & \\
\hline Female & 54.5 & \\
\hline \multicolumn{3}{|l|}{ Head of household race } \\
\hline White & 54.3 & \\
\hline Black & 33.3 & \\
\hline Hispanic & 10.4 & \\
\hline Other & 1.9 & \\
\hline Age (years) & $43.7(15.7)$ & \\
\hline Head of household married & 53.2 & \\
\hline \multicolumn{3}{|l|}{ Education (completed) } \\
\hline Less than high school & 19.4 & \\
\hline Completed high school & 37.6 & \\
\hline Completed some college & 22.4 & \\
\hline Completed college & 20.7 & \\
\hline Number of children & $0.9(1.2)$ & \\
\hline Household pre-tax earned income* (US\$) & $50423(73$ 175) & \\
\hline Eligible for EITC & 31.7 & \\
\hline EITC refund amount* (US\$) & $1701(1577)$ & \\
\hline Panel B: outcomes & Mean (SD) or \% & No. person-years \\
\hline Psychological distress & $3.5(4.1)$ & 59734 \\
\hline Very good/excellent overall health & 53.3 & 289611 \\
\hline Currently drink alcohol & 60.2 & 116066 \\
\hline Consume three or more drinks per day & 13.9 & 115015 \\
\hline Currently smoke & 21.3 & 127246 \\
\hline Cigarettes per day & $2.9(7.2)$ & 126944 \\
\hline
\end{tabular}

$\mathrm{N}=34824$ persons, 289877 person-years.

*Inflation-adjusted.

EITC, earned income tax credit. 


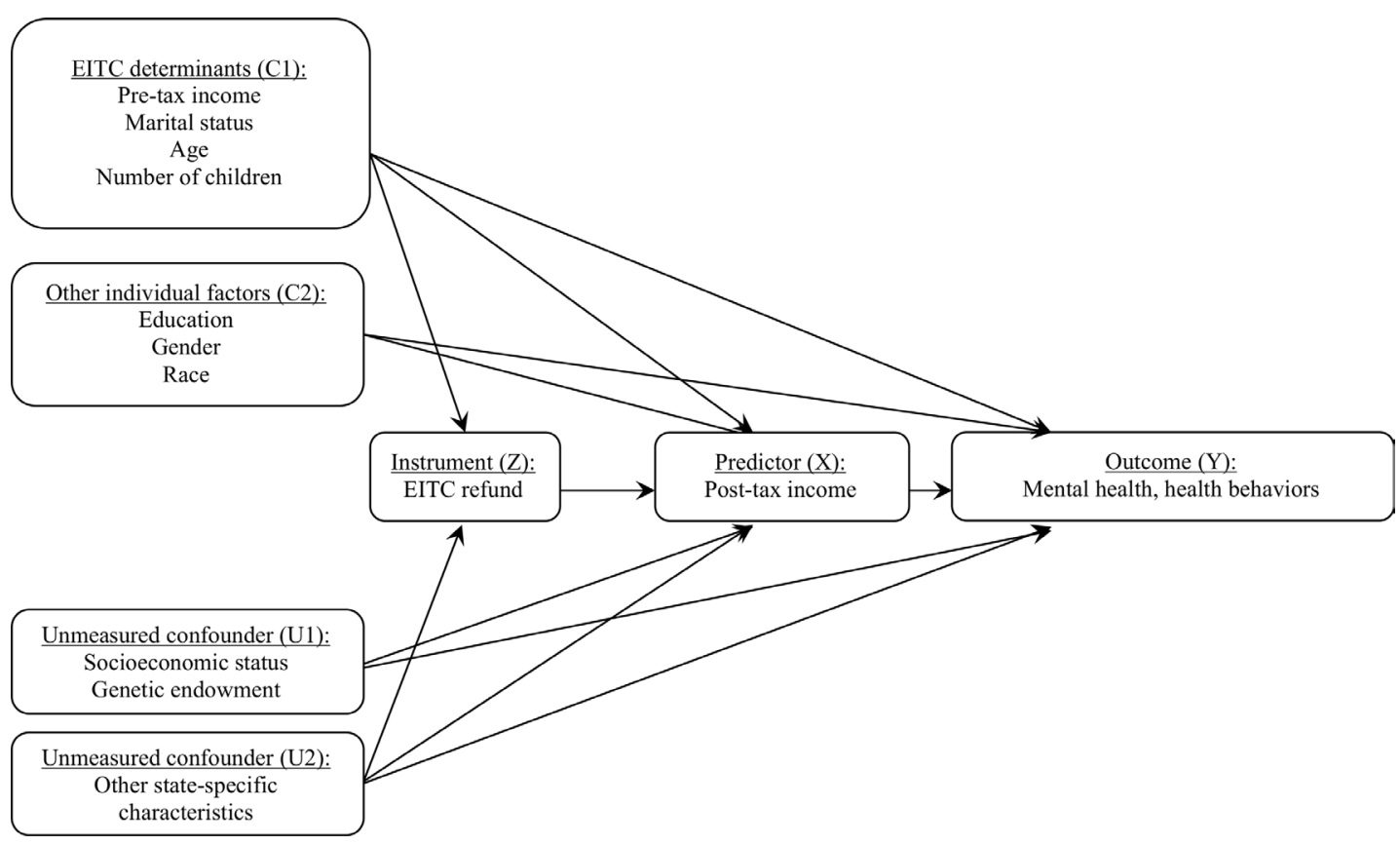

Figure 2 Instrumental variables design. Instrumental variables analysis is useful when the relationship between the exposure (X) and the outcome $(\mathrm{Y})$ is confounded by unmeasured factors $(\mathrm{U})$ and in which the exposure cannot easily be randomised. The method takes advantage of a third variable - the instrument $(\mathrm{Z})$ - which is quasi-randomly assigned and influences the outcome $(\mathrm{Y})$ only through the exposure (X). EITC, earned income tax credit.

refund amounts using Internal Revenue Service formulas. ${ }^{29}$ Inputs included the head of household's age and marital status, household pre-tax earned income, number of children, state of residence, and tax year. Since PSID does not query participants about actual EITC refunds received, we assumed that all eligible households received the tax refund for which they were eligible, an approach used in numerous studies of the EITC. ${ }^{172030}$ This approach may result in measurement error since prior work has shown that roughly $80 \%$ of families receive the EITC refund for which they are eligible ${ }^{31}$; however, it is analogous to an intentto-treat analysis and an alternative to previous studies that used low educational attainment or state EITC implementation as proxies for EITC receipt. ${ }^{19}{ }^{21}$ Coefficients are presented per $\$ 1000$ of EITC, for ease of interpretation.

\section{Covariates}

Covariates included age and age-squared, marital status, education, number of children, inflation-adjusted pre-tax income and income-squared, and indicator variables for year to account for secular trends. Time-invariant covariates like gender and race were not included given the use of individual-level fixed effects, described below.

\section{Data analysis}

We first tabulated participant characteristics. We then carried out two types of analyses: (1) ordinary least squares (OLS), which is subject to confounding of the relationship between income and health by unobserved individual characteristics, and (2) instrumental variables (IV) analysis, which is designed to address such confounding (figure 2 ).

In the first set of OLS models, we regressed each outcome on self-reported income, adjusting for the covariates above. To account for the panel nature of PSID, in which participants are interviewed repeatedly over time, we included fixed effects (ie, indicator variables) for each individual. This technique leverages within-person (rather than across-person) variation in the EITC, which accounts for unobserved time-invariant individual characteristics and strengthens causal inference. Robust SEs were clustered at the individual level to account for correlated observations.

In a second set of OLS models, we regressed each health outcome on EITC refund size, again adjusting for covariates and clustering SEs at the individual level. This model is considered the 'reduced form' of the IV analysis described below.

OLS models are likely to suffer from confounding by unobserved individual factors like socioeconomic status or genetic endowment (figure 2, U1). To address this confounding, we employed IV analysis, a well-established quasi-experimental technique. $^{32}$ IV analysis relies on a quasi-randomly assigned variable or 'instrumental variable'-in this case, the size of the EITC refund for which an individual is eligible (Z)-which impacts the health outcome $(\mathrm{Y})$ through the exposure (X, post-tax household income). This method is useful when the exposure cannot easily be randomised, as in the case of income. IV analysis assumes that there is not a separate pathway linking the instrument and outcome other than through the exposure, nor any unmeasured characteristics that confound the relationship between the instrument and the exposure or outcome. Although these assumptions cannot be empirically verified, we conducted analyses to test these assumptions. Since variation in EITC refund size over time is driven by exogenous policy changes that act through a small set of measured characteristics, which we include as covariates in regressions (C1, eg, pre-tax earned income, marital status), and because we calculate the EITC refund size for which an individual was eligible rather than actual receipt (analogous to an intent-to-treat design), the analysis is, therefore, less likely to suffer from confounding by other measured and unmeasured individual characteristics $(\mathrm{C} 2, \mathrm{U} 1) .{ }^{33}$ Additional details and equations are provided in the online supplemental file. 
We used linear models for all analyses. While logistic models are often more appropriate than linear models when evaluating binary outcomes, in this case, they failed to converge in the presence of individual-level fixed effects due to the large number of variables. Because fixed effects models rely on within-person comparisons and therefore strengthen causal inference, we opted to use linear models with fixed effects even for binary outcomes. The coefficient in these models is therefore interpreted as the change in per cent risk of the outcome per $\$ 1000$ of income.

\section{Secondary analyses}

We performed several additional analyses to test the robustness of results to multiple specifications. First, as prior studies have shown that the EITC may affect single and married individuals differently, ${ }^{22}$ we conducted a stratified analysis with separate models for single and married individuals. Second, we conducted an analysis restricted to participants with annual household incomes greater than US\$0 and less than US\$100 000 $(\mathrm{N}=29813)$, as these are more likely to represent an appropriate comparison group for EITC recipients. Finally, we sought to account for possible residual confounding by unmeasured statelevel characteristics (figure 2, U2); approximately half of states provide an additional EITC refund to supplement the federal refund, and these states may have other characteristics leading to differences in health. To eliminate the possibility of state-level residual confounding, we used only the federal EITC refund size as the instrument. In this analysis, any effect is based solely on variation in the federal refund, thereby removing the possibility of confounding by state characteristics.

\section{RESULTS}

\section{Sample characteristics}

About half of the participants were women, 54.3\% were white, $33.3 \%$ were black, and $10.4 \%$ were Hispanic (table 1). The mean age was 43.7 years (SD 15.7), and 53.2\% were married. Approximately $37.6 \%$ completed high school. The average household pre-tax income was US\$50423 (SD 73 175), and a quarter of participants were eligible for the EITC at some point during the study period. The average income for EITC-eligible recipients was US\$18 061 (SD 11 975), and the average amount of EITC refund for which participants were eligible was US\$1701 (SD 1577). The EITC refund amounted to $9.4 \%$ of recipients' annual pre-tax income on average. The mean psychological distress score was 3.5 (SD 4.1), and 53.3\% reported very good or excellent overall health. About $60.2 \%$ consumed alcohol, and $13.9 \%$ consumed $3+$ drinks per day. About 21.3\% smoked, and the mean number of cigarettes smoked per day was 2.9 (SD 7.2).

\section{Association of income and EITC with outcomes (OLS models)}

Higher income was associated with reduced psychological distress $(-0.026$ per US\$1000, 95\% CI: -0.035 to -0.018$)$, increased probability of consuming alcohol $(0.0098,95 \% \mathrm{CI}$ : 0.00047 to 0.0015$)$, and increased cigarettes smoked per day (0.012, 95\% CI: 0.0056 to 0.019) (table 2, Model 1).

Meanwhile, larger EITC refunds were associated with reduced psychological distress $(-0.070$ per US $\$ 1000,95 \% \mathrm{CI}:-0.11$ to -0.031 ) but not other outcomes (table 2, Model 2).

\section{The effect of income on outcomes (IV models)}

In IV models, higher income was associated with decreased psychological distress $(-0.13$ per US $\$ 1000,95 \% \mathrm{CI}$ : -0.21 to -0.059 ) (table 2, Model 3). This represents a decrease of about $3 \%-4 \%$ of a SD in the K6 score. We were unable to reject the null hypothesis that there was no association of income with overall health or alcohol and tobacco use.

\section{Secondary analyses}

When stratifying by marital status, EITC refund size was associated with reduced psychological distress among single households ( -0.098 per US\$1000, 95\% CI: -0.15 to -0.047$)$, and this was statistically significantly different from the estimate for married households $(0.16,95 \% \mathrm{CI}$ : -0.27 to $0.59, \mathrm{p}<0.001)$ (table 3, Models 1-2). For other outcomes, estimates for single and married individuals were similar.

Restricting the sample to households with income over US\$0 and under US\$100000 (table 3, Model 3), we were unable to reject the null hypothesis of no association of income with any

Table 2 Association of income and the EITC refund size with mental health and health behaviours

\begin{tabular}{|c|c|c|c|}
\hline Outcome & $\begin{array}{l}\text { Model 1: } \\
\text { association of income with health (OLS) }\end{array}$ & $\begin{array}{l}\text { Model 2: } \\
\text { association of EITC with health (OLS) }\end{array}$ & $\begin{array}{l}\text { Model 3: } \\
\text { effect of income on health (IV) }\end{array}$ \\
\hline Psychological distress & $\begin{array}{l}-0.026^{* *} \\
(-0.035 \text { to }-0.018)\end{array}$ & $\begin{array}{l}-0.070^{*} \\
(-0.11 \text { to }-0.031)\end{array}$ & $\begin{array}{l}-0.13^{* *} \\
(-0.21 \text { to }-0.059)\end{array}$ \\
\hline Very good/excellent health & $\begin{array}{l}0.0013^{* *} \\
(0.00085 \text { to } 0.0018)\end{array}$ & $\begin{array}{l}0.0000046 \\
(-0.0027 \text { to } 0.0027)\end{array}$ & $\begin{array}{l}-0.0028 \\
(-0.0096 \text { to } 0.0040)\end{array}$ \\
\hline Currently drink alcohol & $\begin{array}{l}0.00098^{* *} \\
(0.00047 \text { to } 0.0015)\end{array}$ & $\begin{array}{l}0.0025 \\
(-0.00039 \text { to } 0.0055)\end{array}$ & $\begin{array}{l}0.011 \\
(-0.0023 \text { to } 0.025)\end{array}$ \\
\hline $3+$ drinks per day & $\begin{array}{l}-0.00012 \\
(-0.00053 \text { to } 0.00030)\end{array}$ & $\begin{array}{l}-0.0016 \\
(-0.0039 \text { to } 0.00078)\end{array}$ & $\begin{array}{l}-0.0071 \\
(-0.018 \text { to }-0.0038)\end{array}$ \\
\hline Currently smoke & $\begin{array}{l}0.0018 \\
(-0.00013 \text { to } 0.00050)\end{array}$ & $\begin{array}{l}0.00086 \\
(-0.0012 \text { to } 0.0029)\end{array}$ & $\begin{array}{l}0.0044 \\
(-0.0060 \text { to } 0.015)\end{array}$ \\
\hline Cigarettes per day & $\begin{array}{l}0.012^{* *} \\
(0.0056 \text { to } 0.019)\end{array}$ & $\begin{array}{l}0.0022 \\
(-0.033 \text { to } 0.038)\end{array}$ & $\begin{array}{l}0.011 \\
(-0.17 \text { to } 0.19)\end{array}$ \\
\hline
\end{tabular}

Study sample was drawn from the Panel Study of Income Dynamics for survey years 1985-2015. All models involved multivariable linear regressions, adjusting for age and age-squared, education, marital status, number of children, household inflation-adjusted pre-tax earned income and income-squared, year fixed effects, and individual fixed effects. Robust SEs were clustered at the individual level. Coefficients are presented per US\$1000 of income or EITC.

Model 1 represents the OLS model, regressing each outcome on pre-tax inflation-adjusted household income.

Model 2 represents the reduced form of the IV analysis, regressing each outcome on EITC refund size.

Model 3 represents the IV analysis, with EITC refund size as the instrument for post-tax inflation-adjusted household income.

${ }^{*} p<0.05,{ }^{* *} p<0.01$.

EITC, earned income tax credit; IV, instrumental variable; OLS, ordinary least squares. 
Table 3 Effect of income on mental health and health behaviours, instrumental variables secondary analyses

\begin{tabular}{|c|c|c|c|c|}
\hline Outcome & $\begin{array}{l}\text { Model 1: } \\
\text { single }\end{array}$ & $\begin{array}{l}\text { Model 2: } \\
\text { married }\end{array}$ & $\begin{array}{l}\text { Model 3: } \\
\text { income-restricted }\end{array}$ & $\begin{array}{l}\text { Model 4: } \\
\text { federal EITC }\end{array}$ \\
\hline Psychological distress & $\begin{array}{l}-0.098^{* *} \\
(-0.15 \text { to }-0.047)\end{array}$ & $\begin{array}{l}0.16 \\
(-0.27 \text { to } 0.59)\end{array}$ & $\begin{array}{l}-0.049 \\
(-0.098 \text { to } 0.0013)\end{array}$ & $\begin{array}{l}-0.13^{* *} \\
(-0.20 \text { to }-0.049)\end{array}$ \\
\hline Very good/excellent health & $\begin{array}{l}0.0046 \\
(-0.0032 \text { to } 0.012)\end{array}$ & $\begin{array}{l}0.0046 \\
(-0.0032 \text { to } 0.012)\end{array}$ & $\begin{array}{l}-0.00036 \\
(-0.0045 \text { to } 0.0038)\end{array}$ & $\begin{array}{l}-0.0013 \\
(-0.021 \text { to } 0.018)\end{array}$ \\
\hline Currently drink alcohol & $\begin{array}{l}0.0026 \\
(-0.0023 \text { to } 0.0075)\end{array}$ & $\begin{array}{l}-0.0067 \\
(-0.022 \text { to } 0.0089)\end{array}$ & $\begin{array}{l}0.0035 \\
(-0.00032 \text { to } 0.0074)\end{array}$ & $\begin{array}{l}0.012 \\
(-0.0019 \text { to } 0.026)\end{array}$ \\
\hline Drink 3+ drinks per day & $\begin{array}{l}-0.0039 \\
(-0.0079 \text { to } 0.000061)\end{array}$ & $\begin{array}{l}-0.0028 \\
(-0.015 \text { to } 0.0091)\end{array}$ & $\begin{array}{l}-0.0023 \\
(-0.0056 \text { to } 0.0009)\end{array}$ & $\begin{array}{l}-0.0075 \\
(-0.019 \text { to } 0.0038)\end{array}$ \\
\hline Currently smoke & $\begin{array}{l}0.00024 \\
(-0.0031 \text { to } 0.0036)\end{array}$ & $\begin{array}{l}-0.0019 \\
(-0.0097 \text { to } 0.0060)\end{array}$ & $\begin{array}{l}0.00078 \\
(-0.0019 \text { to } 0.0035)\end{array}$ & $\begin{array}{l}0.0049 \\
(-0.0062 \text { to } 0.016)\end{array}$ \\
\hline Cigarettes per day & $\begin{array}{l}-0.017 \\
(-0.070 \text { to } 0.036)\end{array}$ & $\begin{array}{l}-0.054 \\
(-0.22 \text { to } 0.11)\end{array}$ & $\begin{array}{l}-0.0053 \\
(-0.054 \text { to } 0.044)\end{array}$ & $\begin{array}{l}0.010 \\
(-0.18 \text { to } 0.20)\end{array}$ \\
\hline
\end{tabular}

Study sample was drawn from the Panel Study of Income Dynamics for survey years 1985-2015.

Model 1 is an IV model and restricts the analysis to single heads of household.

Model 2 is an IV model and restricts the analysis to married heads of household.

Model 3 is an IV model and restricts the analysis to households with income above US\$0 and below US\$100000.

Model 4 is an IV model and uses only federal EITC as the instrumental variable.

All models adjusted for age and age-squared, education, marital status, number of children, household inflation-adjusted pre-tax earned income and income-squared, year fixed effects, and individual fixed effects. Robust SEs were clustered at the individual level.

${ }^{*} p<0.05 ;{ }^{* *} p<0.01$

EITC, earned income tax credit; IV, instrumental variable.

outcome, and in several cases (eg, alcohol consumption and smoking), the direction of the effect estimate was different from the primary models. Using federal EITC refund size as the instrument to overcome residual state-level confounding (table 3, Model 4), results were similar to primary models: higher income was associated with lower psychological stress $(-0.13$ per US\$1000, 95\% CI: -0.20 to -0.049 ).

\section{DISCUSSION}

This study examined the effects of income on mental health and health behaviours in a large national sample of US adults, leveraging variation in the EITC and quasi-experimental analyses to reduce confounding present in prior correlational studies.

OLS models suggested that income and the EITC are associated with reduced psychological distress, while income was also associated with improved self-reported health and increased alcohol consumption and cigarettes smoked per day. Prior studies have found that the EITC has beneficial effects on mental health, including depressive symptoms and suicide. ${ }^{21} 34$ Other work has also suggested increased substance use after receipt of governmental benefits, ${ }^{24}$ though recent studies found no short-term effects of the EITC in particular on smoking or alcohol consumption or reductions in smoking. ${ }^{1725}$ There may be several explanations for these contrasting findings. For analyses of the EITC, the annual lump-sum EITC tax refund may be spent differently from income obtained more regularly through employment or other sources, such that its effects on overall health and health behaviours may operate through different pathways. Indeed, prior work suggests that the EITC is often spent on large appliances and reducing debt. ${ }^{35}$ Alternatively, it may be that the relationship between income and these outcomes is confounded in OLS models by time-varying individual or place-based characteristics that influence income as well as mental health and health behaviours.

The IV models attempted to address this confounding by using EITC refund size as an instrument for household income. We found that income reduced psychological distress and point estimates for other outcomes were largely similar to OLS models for the EITC, but CIs included the null. This may be due to the imprecision involved in estimating the two stages of the IV analysis, which increases SEs. Alternately, it may be that OLS models of the effects of income are confounded, and that income's actual effects are more limited than correlational analyses would suggest. Again, it may also be that income from the EITC has different effects than income from other sources.

While results from our primary IV models may also be explained by residual confounding from state-level characteristics that confound the association between the EITC and health, findings were similar when considering only the federal EITC refund as the instrument. Results were not robust to the restriction of the sample to individuals with incomes greater than US $\$ 0$ and less than US\$100000. This may be due to a loss of power, since this sample was 15\% smaller than our overall sample; however, it may also be that the overall sample is not an appropriate control group for EITC recipients and that restricting to those who are more likely to be eligible for the EITC addresses an important source of bias in our primary analyses. Additinoally, the finding of improved mental health particularly among single individuals reinforces that the benefit may be particularly salient for this vulnerable group.

Our results corroborate findings that income and the EITC are associated with improved mental health. ${ }^{2122}$ The size of the effect estimate for psychological distress is about $2 \%-3 \%$ of a SD per US $\$ 1000$, representing a meaningful change at the population level. Our results are consistent with two prior studies finding no effect on alcohol use, ${ }^{1725}$ and contradicts prior evidence that the EITC reduces smoking. ${ }^{1723}$ Since our study uses more recent data, it may be that this association has changed over time as smoking rates in the US decline, ${ }^{37}$ and the social safety net has changed. However, it may be that prior studies do not accurately capture the population of EITC recipients because of the use of crude proxies for EITC eligibility (eg, educational attainment), and our results represent a more accurate estimate of policy effects. Studies have shown that the links between socioeconomic status and health behaviours may depend on appropriate adjustment for confounders, suggesting that more rigorous analytical methods are needed. ${ }^{38}$ Future studies should attempt to replicate these findings in more recent cohorts and with different 
study designs, and results should be contrasted with studies that provide income in more frequent disbursements.

There are several limitations to this study. First, we assumed that all participants received EITC refunds if eligible, which is likely to introduce misclassification. Since national surveys rarely include questions on EITC receipt, this technique is commonly used in the literature, analogous to an intent-to-treat approach and an alternative to prior studies that use educational attainment as a proxy for EITC eligibility. Second, IV analyses assume that there is no other pathway linking the instrument and outcomes other than income; in this case, changes in employment as a result of the EITC may represent one such violation of this assumption, so results should be interpreted cautiously. Third, there may be measurement error as demographic and outcome data were self-reported. PSID includes a limited number of health outcomes, and therefore we were unable to examine other operationalisations of mental health such as depressive symptoms or self-sufficiency. The analysis may also suffer from time-varying confounding, if EITC refunds received in one wave affect EITC determinants (eg, marital status) in future waves; unfortunately, while we adjust for these measured characteristics in our models, IV analysis is not compatible with marginal structural models or other types of analyses that account for this type of confounding. Future studies should attempt to validate our findings using alternative modelling strategies. Finally, IV analysis represents a 'local average treatment effect', ${ }^{39}$ and results therefore may not generalise to income received through other means or across income ranges, for example, to higher-income or unemployed households.

Our study contributes to the literature on the health effects of income and provides evidence on the impact of one of the largest US poverty alleviation policies on health. The findings enhance our theoretical understanding of the effects of income on mental health and health behaviours and help inform policymaking on a population-level intervention that may reduce socioeconomic disparities in health. These findings also complement work showing that state EITC supplements are cost-effective and are associated with improvements in health-related quality of life and longevity, important insights for advancing policy discussions on the EITC. ${ }^{40}$

\section{What is already known on this subject}

- Poverty has repeatedly been linked with a greater risk of mental health and health behaviours. Yet most evidence is correlational, and there is limited evidence in the US on the effects of specific interventions and policies to improve health by addressing poverty itself.

\section{What this study adds}

- Using a large diverse national data set and a quasiexperimental design, this study examined the effects of the earned income tax credit (EITC) - the largest US poverty alleviation programme - on mental health and health behaviours. Increased income was associated with reduced psychological distress, increased drinking, and increased smoking, although models that leveraged the quasi-random variation in the EITC found an association only with reduced psychological distress. Since it is contingent on employment and distributed as a lump sum, the EITC may have different health effects than other policies to increase income through other mechanisms.
Future research could examine other mental health outcomes or income supplementation programmes implemented differently (eg, the minimum wage or basic income not linked to employment).

Twitter Laura Shields-Zeeman @shieldsy_and Rita Hamad @DrRitaHamad

Contributors $\mathrm{RH}$ conceived of the study. $\mathrm{LS}-\mathrm{Z}, \mathrm{DC}$, and $\mathrm{AB}$ contributed to data cleaning and analysis. LS-Z created the first draft of the manuscript. All authors contributed to interpretation of the results, critically revised the manuscript and approved of the final version.

Funding This work was supported by grants from the UCSF Hellman Fellows Fund, the UCSF Irene Perstein Award and the UCSF National Centre of Excellence in Women's Health. The collection of Panel Study of Income Dynamics data used in this study was partly supported by the National Institutes of Health (grant number R01HD069609 and R01AG040213), and the National Science Foundation (award numbers SES 1157698 and 1623684).

Disclaimer The study funders had no role in study design; collection, analysis and interpretation of data; writing the report; and the decision to submit the report for publication.

\section{Competing interests None declared.}

\section{Patient consent for publication Not required.}

Ethics approval Ethical approval was not required, as this study was conducted using public de-identified data.

Provenance and peer review Not commissioned; externally peer reviewed.

Data availability statement Data are available in a public, open access repository. The source data for this study are publicly available from the website of the Panel Study of Income Dynamics, https://psidonline.isr.umich.edu.

Supplemental material This content has been supplied by the author(s). It has not been vetted by BMJ Publishing Group Limited (BMJ) and may not have been peer-reviewed. Any opinions or recommendations discussed are solely those of the author(s) and are not endorsed by BMJ. BMJ disclaims all liability and responsibility arising from any reliance placed on the content. Where the content includes any translated material, BMJ does not warrant the accuracy and reliability of the translations (including but not limited to local regulations, clinical guidelines, terminology, drug names and drug dosages), and is not responsible for any error and/or omissions arising from translation and adaptation or otherwise.

\section{ORCID iD}

Rita Hamad http://orcid.org/0000-0003-0730-4077

\section{REFERENCES}

1 Braveman P, Gottlieb L. The social determinants of health: it's time to consider the causes of the causes. Public Health Rep 2014;129(Suppl 2):19-31.

2 Adler NE, Glymour MM, Fielding J. Addressing social determinants of health and health inequalities. JAMA 2016;316:1641-2.

3 Patel V, Burns JK, Dhingra M, et al. Income inequality and depression: a systematic review and meta-analysis of the association and a scoping review of mechanisms. World Psychiatry 2018;17:76-89.

4 Weinberger $\mathrm{AH}$, Gbedemah M, Martinez AM, et al. Trends in depression prevalence in the USA from 2005 to 2015: widening disparities in vulnerable groups. Psychol Med 2018;48:1308-15.

5 Schilbach F, Schofield H, Mullainathan S. The psychological lives of the poor. Am Econ Rev 2016;106:435-40.

6 Khullar D, Chokshi DA. Health, Income, \& Poverty: Where we are \& what could help. Heal Aff Heal Policy Br 2018.

7 Kassel JD, Stroud LR, Paronis CA. Smoking, stress, and negative affect: correlation, causation, and context across stages of smoking. Psychol Bull 2003;129:270-304.

8 Kanjilal S, Gregg EW, Cheng YJ, et al. Socioeconomic status and trends in disparities in 4 major risk factors for cardiovascular disease among US adults, 1971-2002. Arch Intern Med 2006;166:2348-55.

9 Catalano R, McConnell W, Forster P, et al. Does the disbursement of income increase psychiatric emergencies involving drugs and alcohol? Health Serv Res 2000;35:813-323.

10 White JS, Basu S. Does the benefits schedule of cash assistance programs affect the purchase of temptation goods? Evidence from Peru. J Health Econ 2016;46:70-89.

11 Adler NE, Newman K. Socioeconomic disparities in health: pathways and policies. Health Aff 2002;21:60-76.

12 Internal Revenue Service. Statistics for tax returns with EITC | EITC \& Other Refundable Credits. Cal. Half Year Rep, 2018. Available: https://www.eitc.irs.gov/eitccentral/statistics-for-tax-returns-with-eitc/statistics-for-tax-returns-with-eitc [Accessed 15 Jul 2019].

13 Center on Budget and Policy Priorities. The earned income tax credit 2019 
14 Chetty R, Friedman JN, Saez E. Using differences in knowledge across neighborhoods to uncover the impacts of the EITC on earnings. Am Econ Rev 2013;103:2683-721.

15 Meyer BD, Rosenbaum DT. Welfare, the earned income tax credit, and the labor supply of single mothers. Q J Econ 2001;116:1063-114.

16 Pilkauskas N, Michelmore K. The effect of the earned income tax credit on housing and living arrangements. Demography 2019;56:1303-26.

17 Rehkopf DH, Strully KW, Dow WH. The short-term impacts of earned income tax credit disbursement on health. Int J Epidemiol 2014;43:1884-94.

18 Lenhart 0 . The effects of income on health: new evidence from the earned income tax credit.. Rev Econ Househ 2018.

19 Hoynes H, Miller D, Simon D. Income, the earned income tax credit, and infant health. Am Econ J Econ Policy 2015;7:172-211.

20 Hamad R, Collin DF, Baer RJ, et al. Association of revised WIC food package with perinatal and birth outcomes: a quasi-experimental study. JAMA Pediatr 2019;173:845-52.

21 Dow WH, Godøy A, Lowenstein CA. Can economic policies reduce deaths of despair? NBER Work Pap 2019:25787.

22 Evans WN, Garthwaite CL. Giving mom a break: the impact of higher EITC payments on maternal health. Am Econ J Econ Policy 2014;6:258-90.

23 Pega F, Carter K, Blakely T, et al. In-work tax credits for families and their impact on health status in adults. Cochrane Database Syst Rev 2013:CD009963.

24 Kenkel DS, Schmeiser MD, Urban C. Is smoking inferior? Evidence from variation in the earned income tax credit. J Hum Resour 2014;49:1094-120.

25 Collin DF, Shields-Zeeman LS, Batra A, et al. Short-term effects of the earned income tax credit on mental health and health behaviors. Prev Med 2020;139:106223.

26 Survey Research Center Institute for Social Research University of Michigan Ann Arbor Michigan. Panel study of income dynamics, public use dataset, 2018.

27 Kessler RC, Andrews G, Colpe LJ, et al. Short screening scales to monitor population prevalences and trends in non-specific psychological distress. Psychol Med 2002;32:959-76.
28 Jylhä M. What is self-rated health and why does it predict mortality? Towards a unified conceptual model. Soc Sci Med 2009;69:307-16.

29 Feenberg D, Coutts E. Association for public policy analysis and management an introduction to the TAXSIM model. Source J Policy Anal Manag 1993;12:189-94.

30 Hamad R, Rehkopf DH. Poverty, pregnancy, and birth outcomes: a study of the earned income tax credit. Paediatr Perinat Epidemiol 2015;29:444-52.

31 IRS. EITC participation rate by states. EITC other Refund. credit, 2019. Available: https://www.eitc.irs.gov/eitc-central/participation-rate/eitc-participation-rate-by-states [Accessed 11 Jun 2019].

32 Glymour MM. Natural experiments and instrumental variable analyses in social epidemiology.. In: Oakes M, Kaufman JS, eds. Methods in social epidemiology. San Francisco: Jossey-Bass, a Wiley Imprint, 2006: 429-61.

33 Hamad R, Rehkopf DH. Poverty and child development: a longitudinal study of the impact of the earned income tax credit. Am J Epidemiol 2016;183:775-84.

34 Boyd-Swan C, Herbst CM, Ifcher J, et al. The earned income tax credit, mental health, and happiness. J Econ Behav Organ 2016;126:18-38.

35 Mendenhall R, Edin K, Crowley S, et al. The role of earned income tax credit in the budgets of low-income households. Soc Serv Rev 2012;86:367-400.

36 Goodman-Bacon A, McGranahan L. How do EITC recipients spend their refunds? Econ Perspect 2008;2Q:17-33.

37 Public Health Service Office of the Surgeon General. Re: smoking cessation: a report of the surgeon General. Rockville, MD, 2020.

38 Hamad R, Brown DM, Basu S. The association of county-level socioeconomic factors with individual tobacco and alcohol use: a longitudinal study of U.S. adults. BMC Public Health 2019;19:1-11.

39 Imbens GW. Better LATE than nothing: some comments on Deaton (2009) and Heckman and Urzua (2009). J Econ Lit 2010;48:399-423.

40 Muennig PA, Mohit B, Wu J, et al. Cost effectiveness of the earned income tax credit as a health policy investment. Am J Prev Med 2016;51:874-81. 